\title{
Asymmetric admixture and morphological variability at a suture zone: parapatric burbot subspecies (Pisces) in the Mackenzie River basin, Canada
}

\author{
Kathryn R. Elmer • Hans Recknagel • \\ Amy Thompson - Axel Meyer
}

\begin{abstract}
The burbot (Lota lota L.) is a northern freshwater fish with a circumpolar distribution. Two subspecies diverged due to isolation during glacial maxima: Lota lota lota is the Eurasian-Beringian subspecies and Lota lota maculosa the North American subspecies. We sampled burbot from the Great Slave Lake and Mackenzie River area, Canada, the only known contact zone of these two lineages. Using molecular methods (microsatellite loci and mtDNA sequence) we found that the subspecies' distributions abut in the Mackenzie River delta, with L. l. lota in the lower delta and L. l. maculosa in all upstream rivers and lakes. Admixture between subspecies was minimal, decreased with increasing geographic distance, and was asymmetrical: mitochondrial and nuclear genetic introgression was from $L$. $l$. lota into L. l. maculosa but not the reverse. Within subspecies,
\end{abstract}

Handling editor: Christian Sturmbauer

K. R. Elmer · H. Recknagel · A. Meyer (西)

Lehrstuhl für Zoologie Und Evolutionsbiologie, Department of Biology, University of Konstanz, Universitätstrasse 10, 78457 Constance, Germany e-mail: axel.meyer@uni-konstanz.de

\section{A. Thompson}

Gwich'in Renewable Resources Board, PO Box 2240, Inuvik, NT XOE 0T0, Canada there was low inter-population genetic differentiation, no isolation-by-distance, and no evidence for sexbiased dispersal. We did not identify a difference in body length between subspecies per se, though mean lengths differed among localities. Thus, genetic data demonstrate that burbot subspecies are reproductively isolated though the extent to which morphologically variability relates to local versus subspecific variation remains unclear.

Keywords Burbot - Mackenzie River - Population genetics - Subspecies - Microsatellites - mtDNA

\section{Introduction}

Glaciation events dramatically and repeatedly altered the northern landscape and, as they did so, left an imprint of cyclical isolation and contact on the evolutionary history of northern biota (Bernatchez \& Wilson, 1998; Hewitt, 2001). During glacial maxima, freshwater fish populations were relegated to various refugia beyond the reach of the ice sheets and this resulted in diversification of isolated, independent populations by drift and selection. When isolation was relatively brief, conspecific fish populations freely admixed again upon contact, though the genetic signal of glacial isolation can still be detected (e.g. Stepien \& Faber, 1998; Nesbø et al., 1999; Gum et al., 2005; Barluenga et al., 2006; Elmer et al., 2008). When glaciation and concomitant periods of isolation 
extended many thousands of generations, greater genetic and evolutionary diversification accumulated.

Populations of the northern freshwater fish, the burbot Lota lota (L.) (Gadiformes: Lotidae), were separated for multiple glacial cycles and thus diverged into two lineages (Van Houdt et al., 2003). Today, the distribution of the burbot spans the holarctic and two parapatric and genetically distinct subspecies are described: Lota lota lota (=Lota lota kamensis Markun (1936)) across Eurasia-Beringia and Lota lota maculosa (LeSueur, 1817) restricted to North America (Van Houdt et al., 2003, 2005; Elmer et al., 2008). The subspecies appear to be morphologically very similar; characters such as caudal-peduncle ratio, the size of the pectoral fins, and number of pyloric caeca have been suggested to be able to discern them (e.g. Pivnicka, 1970; McPhail \& Paragamian, 2000) but many authors (e.g. McPhail \& Lindsey, 1970; Scott \& Crossman, 1973) declined to distinguish between putative subspecies because supposedly diagnostic traits are geographically and clinally variable. Whether this variability is due to admixture among subspecies, phenotypic plasticity (Fisher et al., 1996), or local adaptation is unknown.

The two burbot subspecies abut in northwestern Canada as a relict of their most recent post-glacial expansion. Lota l. lota expanded from Beringia (Van Houdt et al., 2005; Elmer et al., 2008) along an eastward colonisation route that is well known for water and land animals, including humans (reviewed in Hewitt, 2004). Lota l. maculosa dispersed north from southern North American refugia such as Mississippi, Missouri and Pacific (Elmer et al., 2008; Powell et al., 2008), probably via proglacial Lake Agassiz as did many other fish species (Pielou, 1991; Rempel \& Smith, 1998; Turgeon \& Bernatchez, 2001). Previous studies suggested admixture may be very low between burbot subspecies, which were speculated to contact in an unknown location and to an unknown extent in the extensive Mackenzie River drainage (Pivnicka, 1970; Elmer et al., 2008).

The Mackenzie is Canada's largest river and at its lower reaches forms a uniquely productive Arctic delta with $\sim 45,000$ lakes (Squires et al., 2009). This is an area of postglacial parapatry for several deeply divergent clades of animals: such 'suture zones' are evolutionarily and biogeographically interesting sites to compare genetic diversity, hybrid variants, reproductive isolation and reinforcement among weakly isolated species (Abbott et al., 2000; Hewitt, 2004; Swenson \& Howard, 2004). Suture zones exist when historical expansion from glacial refugia is consistent across taxa, and often tend to cluster near major landscape features such as mountains or rivers (reviewed in Hewitt, 2004). First proposed by Remington (1968), these zones involve a band of overlap and hybridization between species or semi-species. A suture zone was proposed to exist in the Mackenzie River basin (Hewitt, 2004), inferred from phylogeographic patterns of other circumpolar animals, such as collared lemming (Fedorov \& Stenseth, 2002), ptarmigan (Holder et al., 1999, 2000), root/tundra vole (Brunhoff et al., 2003), true lemming (Fedorov et al., 2003) and whitefish (McDermid et al., 2007). Consequently, inferring ecological and genetic differentiation between burbot subspecies in the putative Mackenzie delta suture zone may inform us about the evolutionary history of this unusually broadly distributed freshwater gadoid species in particular and the existence and role of suture zones more generally (debated for example in Swenson \& Howard, 2004).

Burbot are great dispersers and some individuals undergo long, synchronised migrations to common spawning sites (McCrimmon, 1959; Breeser et al., 1988; McPhail \& Paragamian, 2000; Slavík \& Bartoš, 2002; Miler \& Fischer, 2004; Slavík et al., 2005). Though difficult to observe in nature, it is thought that spawning occurs in groups of males with a single female (a mating ball) and it almost certainly occurs in large groups or spawning aggregations (McCrimmon, 1959; McPhail \& Paragamian, 2000 and references therein). This behaviour has two implications for population genetic structure, especially in a contact zone. First, if fishes return philopatrically to the same spawning location then one might expect population differentiation at broad spatial scales and no fine-scale structuring (e.g. complete or near panmixia of burbot populations in large lakes such as Lake Constance, Germany (Barluenga et al., 2006) or Great Slave Lake, Canada (Elmer et al., 2008). Second, it may be that sexes are biased in the distance they travel to spawning grounds. Spatially informed population genetic methods can provide insights into the cryptic spawning behaviour of natural burbot populations of either subspecies.

In this study, we tested genetic and morphological differences between the subspecies of this wideranging but poorly understood fish, the burbot. We 
conduct spatially informed population genetic analyses of both subspecies at fine- and broad spatial scales, employing nuclear microsatellite loci and mitochondrial DNA control region sequences. Our aim is to identify the location of the subspecies contact zone, assess whether there is contemporary gene flow between subspecies and, if so, at what spatial scale it is occurring. Second, we also assessed a role of sexbiased dispersal in shaping population genetic structure within both subspecies. Third, we tested for differences between subspecies' morphologies based on size. The extent of ecological and genetic differentiation between subspecies may attest to distinct biologies and evolutionary histories and suggest reasons for their supposed continued differentiation.

\section{Materials and methods}

\section{Sampling}

Burbot were caught by line hooking from localities in the Mackenzie River delta, Great Slave Lake and the Slave River (Table 1; Fig. 1). Samples from the Mackenzie River delta were collected from the Gwich'in Settlement Area (GSA), which was established in 1992 with the signing of the Gwich'in comprehensive Land Claim Agreement. The Gwich'in Renewable Resources Board worked with the community and fishermen to collect and sample burbot from traditional burbot fishing locations. Tissue samples were taken from all individuals. More detailed biological data were collected for a subset of individuals including weight (wet round weight), size (fork length), sex (gonads were also abstracted for fecundity analysis) and age (by extracted otolith analysis) (Table 1).

\section{Genetic data collection}

DNA was extracted from dried fins or ethanolpreserved tissue using Chelex extraction or the Qiagen DNeasy Blood and Tissue Kit. All individuals were genotyped at 11 species-specific microsatellite loci (Sanetra \& Meyer, 2005; Elmer et al., 2008). As in previous research (Elmer et al., 2008), Llo 32 and Llo 13 were discarded from further analysis because of poor genotype quality. Previously published microsatellite data (Elmer et al., 2008) from Great Slave
Lake, Colin Lake and Athabasca River were included in order to augment and reference the sample size of "pure" L. l. maculosa (Table 1). Approximately, 550 base pairs of the mitochondrial $(\mathrm{mt})$ control region were sequenced (Table 1) with primers LProF (Meyer et al., 1994) and 12S5R (GGC GGA TAC TTG CAT GT) using standard PCR conditions. PCR products were cleaned using a FastAP ${ }^{\mathrm{TM}}$ Thermosensitive Alkaline Phophatase dephosphorylation protocol and cycle sequenced in the forward and reverse directions by BigDye Terminator Cycle Sequencing Ready Reaction using standard conditions and the same primers as in the PCR. After cleaning the single stranded product by ethanol precipitation, samples were re-suspended in water and electrophoresed in an ABI3130xl DNA-sequencer (Applied Biosystems).

\section{MtDNA analysis}

Forward and reverse contigs were assembled in Sequencher vers. 4.2.2 (Gene Codes Corp.) and aligned using Clustal X (Larkin et al., 2007). New sequences are deposited in Genbank (JN989562JN989639). Subspecies lineage (Eurasian-Beringian/ L. l. lota or North American/L. l. maculosa, see Van Houdt et al., 2003; Elmer et al., 2008) were inferred by their grouping in a neighbour-joining tree constructed with PAUP*vb11 (Swofford, 2003) considering gaps as missing data. Publicly available mtDNA sequences (Genbank accession numbers: AY656863, AY656865, AY656869, AY656872, AY656873, AY656876, AY656880, EU873158, EU873161) were used to determine subspecies clades in the tree (as previously determined, Van Houdt et al., 2005). In order to construct a haplotype network, an alignment of 312 bp was executed in TCS version 1.21 (Clement et al., 2000). Genetic differentiation between populations was estimated with population pairwise $F_{\mathrm{ST}}$ statistics and significance assessed with 1,000 permutations in Arlequin vers. 3.1 (Excoffier et al., 2005) using the $\sim 300 \mathrm{bp}$ overlap between new and publicly available sequences.

\section{Microsatellite DNA analyses}

Genotyping quality per population was confirmed with Microchecker (van Oosterhout et al., 2004). Linkage disequilibrium and Hardy-Weinberg equilibrium were calculated in Genepop on the Web (Raymond \& Rousset, 1995). Multiple tests were Bonferroni 
Table 1 Burbot sampling information, listed approximately north to south

\begin{tabular}{|c|c|c|c|c|c|c|c|c|c|}
\hline Waterbody & Locality & Abbreviation & $N$ (nuclear) & $N(\mathrm{mtDNA})$ & $N$ (length) & $N$ (age) & Latitude $(\mathrm{N})$ & $\begin{array}{l}\text { Longitude } \\
\text { (W) }\end{array}$ & Collection dates \\
\hline Mackenzie River delta & Inuvik & IN & 90 & 11 & 94 & 50 & $68^{\circ} 23.4^{\prime}$ & $133^{\circ} 52.8^{\prime}$ & $\begin{array}{l}\text { Feb. and May 2007, } \\
\text { Jan. and Feb. } 2008\end{array}$ \\
\hline Mackenzie River delta & Aklavik & $\mathrm{AK}$ & 106 & 17 & 133 & 50 & $68^{\circ} 13.6^{\prime}$ & $134^{\circ} 59.4^{\prime}$ & Nov. 2007, Jan. 2008 \\
\hline Peel River & Fort McPherson & FM & 124 & 13 & 137 & 50 & $67^{\circ} 39.2^{\prime}$ & $134^{\circ} 45.5^{\prime}$ & Nov. 2007, Feb. 2008 \\
\hline Arctic Red River & Tsiigehtchic & TS & 26 & 10 & 28 & - & $67^{\circ} 26.7^{\prime}$ & $133^{\circ} 45.3^{\prime}$ & Nov. 2007 \\
\hline Great Slave Lake & Lutsel K'e & GSL-LK & 13 & 8 & 20 & 20 & $62^{\circ} 24^{\prime}$ & $110^{\circ} 43^{\prime}$ & Oct. 2002 \\
\hline Great Slave Lake & Fort Resolution & GSL-FR & 34 & 12 & 34 & 40 & $61^{\circ} 06^{\prime}$ & $113^{\circ} 44^{\prime}$ & Feb. 2003 , Oct. 2008 \\
\hline Great Slave Lake $^{\mathrm{a}}$ & Simpson Island & GSL-Sim & 25 & 25 & - & - & $61^{\circ} 50^{\prime}$ & $112^{\circ} 30^{\prime}$ & 2001 \\
\hline Great Slave Lake $^{\mathrm{a}}$ & Redclif Island & GSL-Red & 2 & 2 & - & - & $62^{\circ} 26^{\prime}$ & $111^{\circ} 06^{\prime}$ & 2001 \\
\hline Great Slave Lake $^{a}$ & Pine Point & GSL-Pin & 29 & 30 & - & - & $60^{\circ} 58^{\prime}$ & $114^{\circ} 23^{\prime}$ & Unknown \\
\hline Slave River & Fort Smith & SR & 15 & 7 & 20 & 20 & $60^{\circ} 00^{\prime}$ & $111^{\circ} 50^{\prime}$ & Dec. 2002 \\
\hline Colin Lake $^{a}$ (beside Lake Athabasca) & Colin Lake & $\mathrm{COL}$ & 14 & 14 & - & - & $59^{\circ} 33^{\prime}$ & $110^{\circ} 07^{\prime}$ & Unknown \\
\hline Athabasca River ${ }^{a}$ & Lambert Creek & At1 & 9 & 9 & - & - & $53^{\circ} 30^{\prime}$ & $117^{\circ} 00^{\prime}$ & 2001 \\
\hline Athabasca River ${ }^{\mathrm{a}}$ & Lac Beauvert & At2 & 11 & 11 & - & - & $52^{\circ} 55^{\prime}$ & $118^{\circ} 00^{\prime}$ & 2001 \\
\hline
\end{tabular}

All sites lie in the Mackenzie River basin, northwestern Canada. For some analyses, nearby Great Slave Lake (GSL) populations are combined

${ }^{a}$ Previously published in Elmer et al. (2008) 


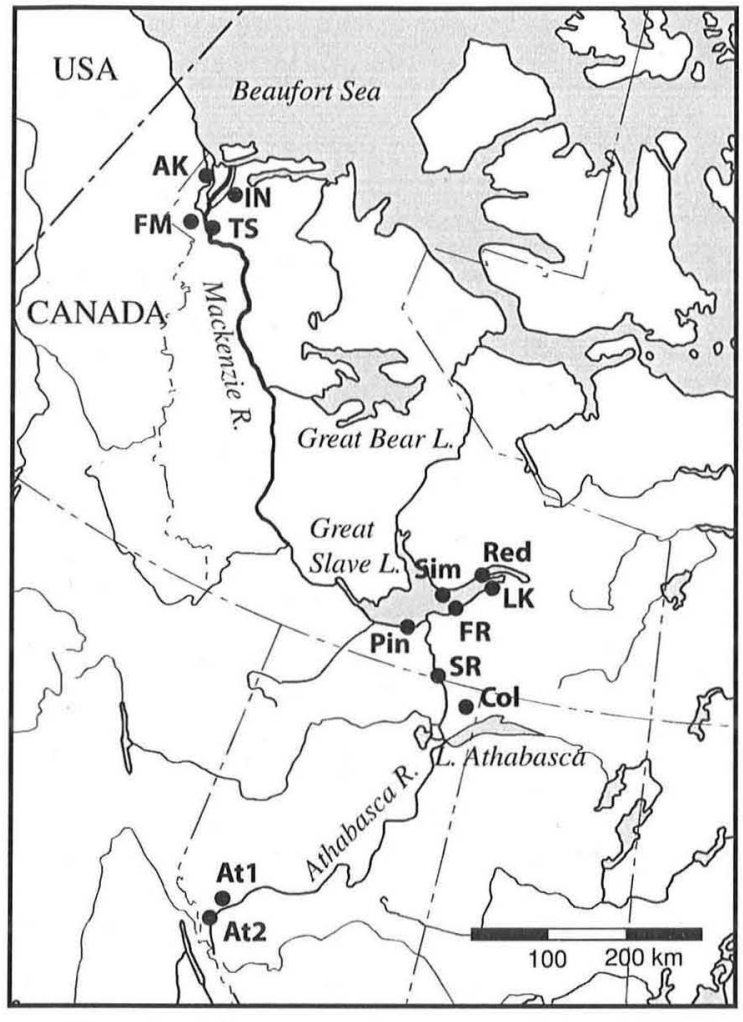

Fig. 1 Map of the Mackenzie River basin of northwestern Canada and surroundings, with sample localities. Locality abbreviations can be found in Table 1

corrected. Genetic diversity statistics were calculated in GenAlEx 6.2 (Peakall \& Smouse, 2006). Allelic richness was rarefied to smallest sample size (nine alleles) with HP Rare vers. 1.0 (Kalinowski, 2005).

Genetic admixture was inferred using Structure vers. 2.2 (Pritchard et al., 2000; Falush et al., 2003). We set $K=2$ to obtain the membership proportion $(Q)$ with $90 \%$ probability interval for each individual towards either subspecies. The analysis was conducted under a model of mixed ancestry. The burn-in period was set to 200,000 generations, followed by 500,000 generations. Five independent iterations were conducted and they converged on identical values.

Population differentiation (spatial and temporal) was calculated by pairwise $F_{\mathrm{ST}}$ using an analysis of molecular variance (AMOVA) in GenAlEx vers. 6 (Peakall \& Smouse, 2006) and the significance assessed through 999 permutations. Geographical distances between populations were calculated following the path of the nearest waterway in Google Earth vers. 5.1 (Google Corporation, 2007). One L. $l$. maculosa individual from AK, two from FM, two from IN and one L. l. lota individual from LK and one from SR were determined post hoc (with Structure analyses) to be considerably $(>50 \%)$ a genetic profile of the other subspecies and therefore excluded from population level genetic diversity analyses.

Sex-biased dispersal was assessed for populations AK, FM, IN, TS and FR by corrected Assignment Index (AIc) (Favre et al., 1997) in FSTAT vers. 2.9.3.2 (Goudet, 1995). AIc mean and variance was compared between males and females with a two-sided $t$-test and significance assessed with 1,000 permutations.

\section{Morphological data}

The variables age, sex, subspecies (genetic proportion, inferred from $Q$ value from nuclear analysis of admixture; see Structure analysis) and locality (with GSL populations combined) were assessed for their influence on total length $(\mathrm{cm})$ in a standard least squares linear model in JMP vers. 5 (SAS, 2008). Starting with a maximal model including age, sex, subspecies, locality and the interactions between age and sex and age, sex and locality, non-significant terms were omitted step-by-step (Crawley, 2007).

\section{Results}

Interannual stability

No significant population genetic differentiation $\left(F_{\mathrm{ST}} \ll 1 \%\right)$ was found when comparing samples from within single localities AK, FM and IN collected over multiple years (Online Resource Table S1; samples with unknown collection dates were excluded). Locality FR, which at 6 years had the greatest interannual sampling time, showed very slight differentiation $\left(F_{\mathrm{ST}}=1.1 \%\right)$ that is not statistically significant after Bonferroni correction. This suggests that there is overall inter-annual stability of these sampled burbot populations. Consequently, samples collected in different years from a single locality were pooled for all subsequent analyses.

Genetic diversity

In agreement with previous studies (Sanetra \& Meyer, 2005; Barluenga et al., 2006; Elmer et al., 2008) none 
of the 36 locus pairs shows significant linkage disequilibrium $(P>0.05)$, indicating that all loci used in this study can be treated as independent markers.

Assignment to subspecies was determined by Structure (see "Admixture" below for more details) and these divisions are used for all subsequent analyses. TS is the only population that was determined post hoc to contain both $L$. l. lota and $L$. $l$. maculosa individuals, and so this locality is split by subspecies for population-based analyses.

At all populations except $\mathrm{AK}$, loci do not deviate from Hardy-Weinberg equilibrium (Table 2). Deviation in AK mainly results from a heterozygote deficiency at a single locus (Llo21, Online Resource Table S2). Rarefied allelic richness ranged from 3.21 to 5.00 average alleles per locus (Table 2) with no average difference between subspecies (mean lota: $4.20 \pm 0.160$, mean maculosa: $4.28 \pm 0.692 ; t=$ $0.216, \mathrm{df}=10, P=0.83$ ). Observed and expected heterozygosities also do not differ between subspecies (Ho.: mean lota $=0.643 \pm 0.016$, mean maculosa $=0.699 \pm 0.069 ; t=1.54, \mathrm{df}=10, P=0.15$; He: mean lota $=0.675 \pm 0.015$, mean maculosa $=$ $0.682 \pm 0.025 ; t=0.164, \mathrm{df}=10, P=0.87$ ).

Of the 78 individuals sequenced for this study, we identified 13 unique haplotypes, 4 of which are new with this study (Table S3). In agreement with previous studies, haplotype diversity is higher in the NA lineage than the EB lineage (Fig. S2). The mutational distance between the EB and the NA lineages is two mutations rather than the five mutations found in previous studies (Van Houdt et al., 2005, Elmer et al., 2008). This difference is due to (i) the different sequenced region and therefore shorter sequence alignment used in this study, and (ii) a new haplotype (NA34), which is one mutation closer to the EB lineage than any previously identified haplotype.

Genetic differentiation between subspecies

Multilocus estimates of genetic differentiation at microsatellite loci and mtDNA sequence between different subspecies are high and significantly differentiated (Table 3). At microsatellite loci, differentiation ranges up to 0.29 between $L$. l. maculosa at Col and L. l. lota at AK. MtDNA $F_{\mathrm{ST}} \mathrm{S}$ range from 0.373 to 0.748 .

Admixture between subspecies

Admixture proportions are consistent with the Mackenzie River being a contact zone between two subspecies of burbot. Very low levels of admixture were found at the individual level (Fig. 2) and the population level (Table 4); most populations and individuals are purely L. l. lota or L. l. maculosa.

At the population level, SR and all GSL populations are L. l. maculosa. Three out of the four populations from the Mackenzie River Delta are genetically purely L. l. lota (AK, IN and FM $<4 \%$ admixture) (Table 4). Lota l. maculosa populations from Great Slave Lake show low levels of admixture (maculosa membership $>95 \%$ ). Upriver of SR there is no admixture $(Q>99 \%)$. The only substantially
Table 2 Summary genetic diversity statistics for each population and subspecies: average number of alleles per locus $(\mathrm{Na})$, average rarefied allelic richness per locus (rarefied $\mathrm{Na}$ ), observed heterozygosity (Ho), expected heterozygosity (He), and deviation from HardyWeinberg equilibrium (HWE)

$n s$ no deviation, ** significant deviation

\begin{tabular}{lllllll}
\hline Population & Subspecies & $\mathrm{Na}$ & Rarefied N & Ho & He & HWE \\
\hline AK & lota & 13.4 & 4.09 & 0.629 & 0.676 & $* *$ \\
IN & lota & 13.6 & 4.12 & 0.637 & 0.692 & $\mathrm{~ns}$ \\
FM & lota & 13.6 & 4.17 & 0.641 & 0.676 & $\mathrm{~ns}$ \\
TS & lota & 4.4 & 4.44 & 0.667 & 0.656 & $\mathrm{~ns}$ \\
TS & maculosa & 11.7 & 4.91 & 0.762 & 0.762 & $\mathrm{~ns}$ \\
FR and Pin & maculosa & 14.8 & 4.82 & 0.750 & 0.758 & $\mathrm{~ns}$ \\
Sim & maculosa & 12.4 & 5.00 & 0.773 & 0.771 & $\mathrm{~ns}$ \\
LK and Red & maculosa & 8.7 & 4.66 & 0.689 & 0.681 & $\mathrm{~ns}$ \\
SR & maculosa & 7.7 & 4.36 & 0.718 & 0.690 & $\mathrm{~ns}$ \\
At1 & maculosa & 5.2 & 3.82 & 0.704 & 0.665 & $\mathrm{~ns}$ \\
At2 & maculosa & 4.3 & 3.21 & 0.591 & 0.566 & $\mathrm{~ns}$ \\
Col & maculosa & 5.7 & 3.48 & 0.603 & 0.563 & $\mathrm{~ns}$ \\
\hline
\end{tabular}




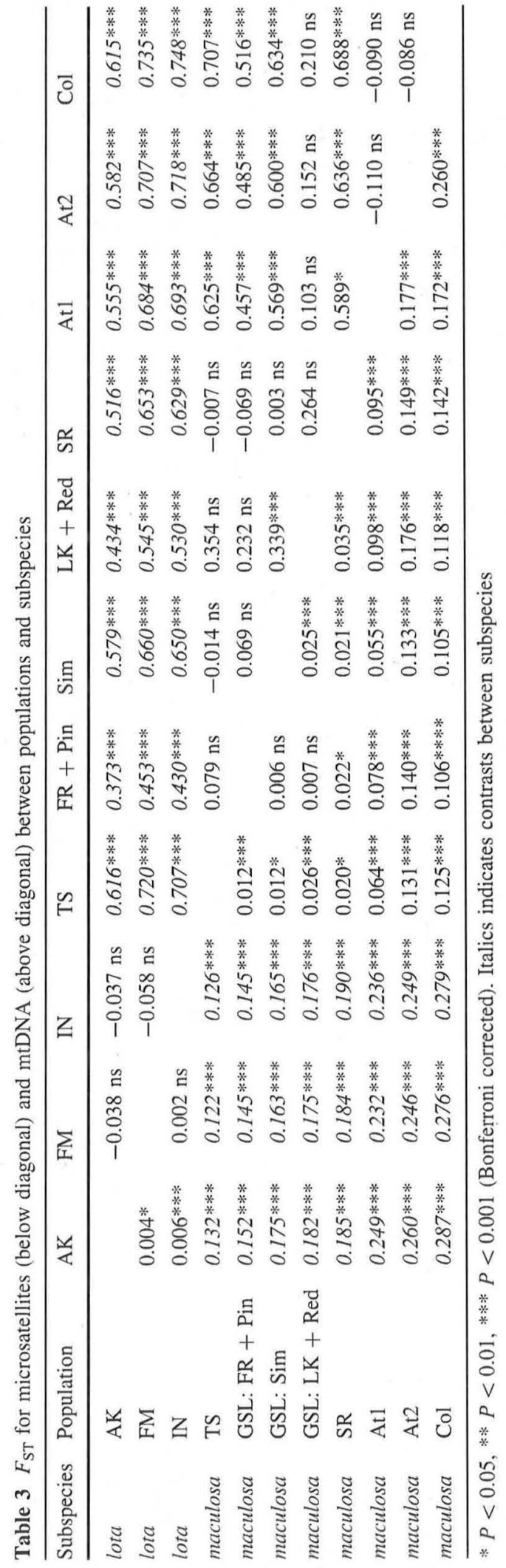

admixed population is TS, because individuals genetically characteristic of each subspecies are found there. Mitochondrial data is mostly congruent with the genotypic data: there is little or no haplotype sharing from the other subspecies in the Mackenzie Basin and some haplotype introgression in GSL and SR (Table 4).

Admixture at the individual level is also low (Fig. 3, Online Resource Fig. S1) and reveals more detailed information than the population-level analyses. Almost all individuals from the Mackenzie basin contact zone show a purely typical $L$. l. lota or $L$. $l$. maculosa genotype profile. Approximately, 20\% of individuals exhibit notable admixture $(Q>0.2$ or $<0.8$ ) when the $90 \%$ probability interval is considered. Allele size homoplasy may inflate admixture proportions; yet the median microsatellite repeat length differs between EB and NA lineages (Elmer et al., 2008) so homoplasy unlikely has a considerable effect. Whereas in all individuals from $L$. $l$. lota genotype populations have lota mtDNA haplotypes, some individuals $(21 \%)$ from $L$. l. maculosa populations, particularly from GSL, have a L. l. lota genotype and a $L$. l. maculosa mtDNA haplotype. This suggests asymmetric introgression. One individual with a $L . l$. maculosa mtDNA haplotype and genotype was found in the $L$. l. lota population AK, which suggests dispersal or an otherwise unsampled local $L$. $l$. maculosa population at $\mathrm{AK}$.

Population genetic structure within subspecies

There is no population genetic differentiation among localities of $L$. l. lota populations, with $F_{\mathrm{ST}}$ less than $1 \%$ for microsatellites and no difference of mtDNA haplotypes (Table 3). Lota l. maculosa populations are more differentiated though also more geographically separated (see "Isolation-by-distance" section). $F_{\mathrm{ST}}$ values among populations downriver (north) of SR are very low $(<0.04)$ but were still statistically significant. Population differentiation is higher among the upriver (Slave River and Athabasca River) populations At1, At2 and $\mathrm{Col}$ and all other populations. MtDNA differentiation among $L$. l. maculosa populations is high, reflecting the greater haplotype richness (Table S3, Fig. S2) resulting from mixing of different glacial refugia in the contemporary Mackenzie River basin (Elmer et al., 2008). 


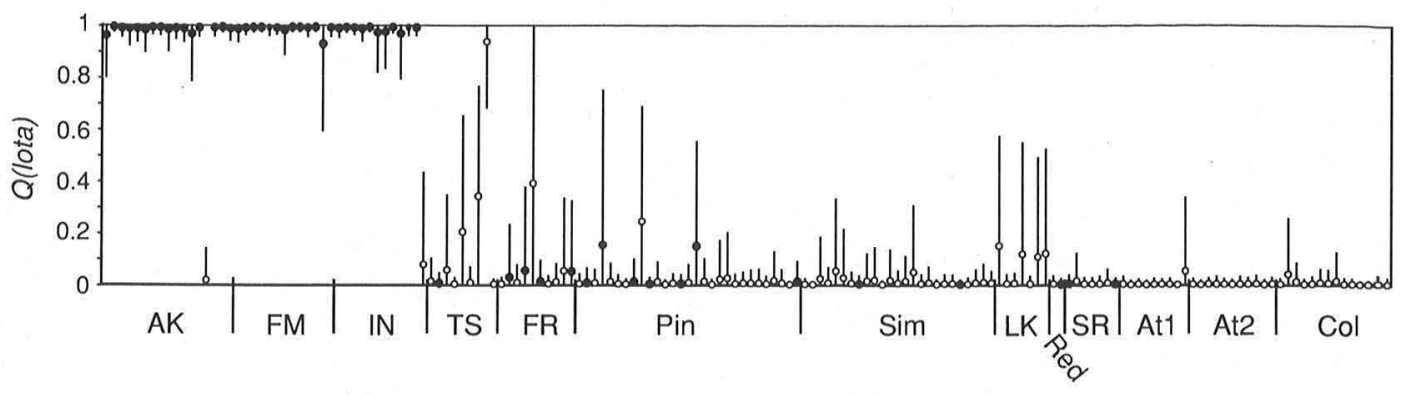

Fig. 2 Admixture analyses demonstrate admixture at the nuclear genome and asymmetrical mitochondrial introgression from L. l. lota (high $Q$ (lota) and black circles) into L. l. maculosa (low $Q($ lota $)$ white circles). Each vertical bar along the $x$-axis represents an individual, with the height of the bars giving the

Table 4 The proportion of each population's sampled nuclear (microsatellites; $n=489$ individuals) and mitochondrial (mtDNA; $n=134$ individuals) genome that is representative of the L. l. lota or L. l. maculosa subspecies genomic signature

\begin{tabular}{llllll}
\hline Population & \multicolumn{2}{l}{ Microsatellites } & & mtDNA \\
\cline { 2 - 3 } \cline { 5 - 6 } & $\begin{array}{l}\text { L. } l . \\
\text { lota }\end{array}$ & $\begin{array}{l}\text { L. } l . \\
\text { maculosa }\end{array}$ & & $\begin{array}{l}\text { L. } l . \\
\text { lota }\end{array}$ & $\begin{array}{l}\text { L. } l . \\
\text { maculosa }\end{array}$ \\
\hline AK & 0.966 & 0.034 & & 0.94 & 0.06 \\
FM & 0.971 & 0.029 & & 0 \\
IN & 0.961 & 0.039 & & 1 & 0 \\
TS & 0.207 & 0.793 & & 0.1 & 0.9 \\
GSL & 0.042 & 0.958 & & 0.22 & 0.78 \\
SR & 0.046 & 0.954 & & 0.29 & 0.71 \\
At & 0.007 & 0.993 & & 0 & 1 \\
Col & 0.010 & 0.990 & & 0 \\
\hline
\end{tabular}

Note that microsatellites represent admixture $(Q$, inferred from Structure analysis) while mtDNA are frequencies of each lineage in the population

\section{Sex-biased dispersal}

The sex that disperses most should have the lowest mean Assignment Index (mAIc) but the highest variance in Assignment Index (vAIc) (Goudet, 1995; Favre et al., 1997). We calculated the corrected AI for burbot populations in the Mackenzie River delta, using populations of both subspecies. We identify no significant difference in the mean AIc between males $(\mathrm{mAIc}=-0.061, n=77)$ and females (mAIc $=$ $0.032, n=146)(P=0.874)$. Further, we find no significant difference in variance between males (vAIc $=$ $14.99)$ and females (vAIc $=17.60)(P=0.716)$. Results are identical when calculated assuming that either females or males are the philopatric sex.
$90 \%$ probability interval. Haplotypes (black or white circles) are coded by inferred phylogroup (following Van Houdt et al., 2005; Elmer et al., 2008). Populations are listed approximately northwest to southeast

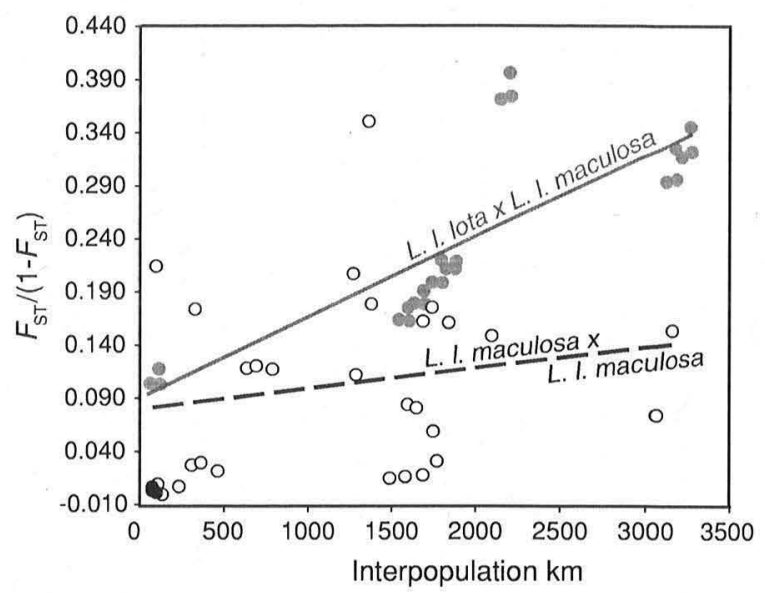

Fig. 3 Pairwise genetic by geographic distances indicate no pattern of isolation-by-distance among populations within either subspecies. However, there is a relationship of increasing genetic similarity among subspecies with proximity, suggestive of admixture. Pairwise contrasts between $L . l$. lota and L. l. maculosa are shown in grey with a grey regression line; contrasts between $L$. l. maculosa and L. l. maculosa are shown in white with a black dashed regression line; contrasts between L. l. lota and L. l. lota are in black

Therefore, we find no indication of sex-biased dispersal in burbot.

\section{Isolation-by-distance}

A comparison of genetic differentiation $\left(F_{\mathrm{ST}} / 1-F_{\mathrm{ST}}\right)$ (Rousset, 1997) by interpopulation geographic distance indicates no significant spatial-genetic relationship within either subspecies (Fig. 3). For L. l. lota, we have little geographical distance between localities, making isolation analyses less informative. However, 
there is a weak negative relationship between genetic and geographic distance but no significant increase or decrease of $F_{\mathrm{ST}}$ and $\mathrm{km}$ and a poor fit between distances $\left(R^{2}\right.$ adjusted $\left.=30.2 \%\right)$. Lota $l$. maculosa shows no correlation between genetic differentiation with geographic distance $\left(R^{2}\right.$ adjusted $\left.=8.4 \%\right)$.

Pairwise contrasts between populations of different subspecies, however, indicate that geographic distance significantly influences genetic differentiation $\left(F_{1,22}=\right.$ 42.83, $P<0.001)$ and there is a strong correlation between variables $\left(R^{2}\right.$ adjusted $\left.=64.5 \%\right)$. This suggests that the signature of admixture between subspecies decreases (i.e., $F_{\mathrm{ST}}$ increases) with geographic distance from the Mackenzie delta contact zone.

\section{Morphology}

The variables age $(F$ ratio $=77.62, \mathrm{df}=1, P<$ $0.0001)$, sex ( $F$ ratio 28.27 , df $=1, P<0.0001$ ) and locality $(F$ ratio $=31.04$, df $=4, P<0.0001)$ determine total length. The variable $Q($ lota $)$ and the interaction terms age * sex, and age * sex * locality were non-significant in the model and eliminated iteratively. In particular, burbot from GSL and SR were smaller than the other populations (Fig. 4), though we could identify no subspecies effect.

For all samples combined (i.e., both subspecies), the sexes differ in length ( $t$ test assuming equal

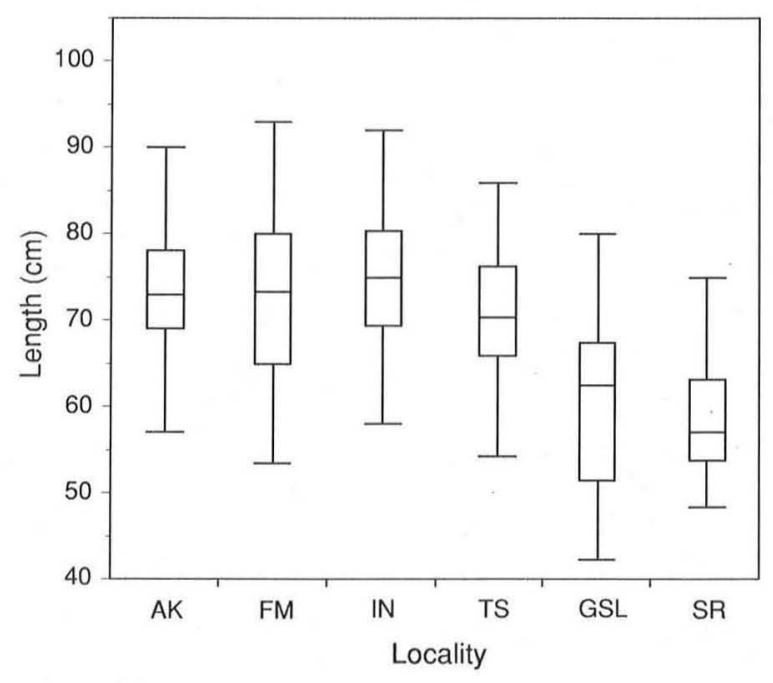

Fig. 4 Total length (in $\mathrm{cm}$ ) differs among burbot sampled from different localities. See Table 1 for locality abbreviations. Populations are listed approximately northwest to southeast variances, $t=7.91 \mathrm{df}=463 \quad P<0.0001)$, with females (mean $73.7 \mathrm{~cm} \pm \mathrm{SD} 9.7 \mathrm{~cm}, n=308$ ) larger than males $(66.5 \mathrm{~cm} \pm 8.7, n=157)$. The age range of fish in our sample spans from 6 to 22 years (mean $13.1 \pm 2.4$ ).

\section{Discussion}

We have identified the location of the genetic contact zone between the two subspecies of burbot and this coincides with a post-glacial 'suture zone' in the lower Mackenzie River Basin. Despite the large circumpolar distribution of the burbot species as a whole, the Eurasian-Beringian subspecies $L$. l. lota and the North American subspecies L. l. maculosa have an abrupt limit to their parapatric distributions and interbreed only very rarely. When there is introgression and admixture between subspecies it is asymmetrical, with gene flow from L. l. lota to L. l. maculosa but not the reverse. These genetic differences are accompanied by morphological differences in body length across localities. There is high gene flow within subspecies, suggestive of considerable dispersal yet without sex-bias.

\section{The Mackenzie River suture zone}

Previous genetic studies, either circumpolar (Van Houdt et al., 2003, 2005) or North American (Elmer et al., 2008) in focus did not locate the limits of either of the widely distributed subspecies $L$. l. lota or L. l. maculosa. Elmer et al. (2008) speculated that the subspecies contact zone would be in north-northwestern Canada, near Great Slave Lake. Based on morphology and meristics, Pivnicka (1970) located the contact zone to be further south in Canada $\left(\sim 55^{\circ} \mathrm{N}\right)$.

In this study, we have located the major contact zone between burbot subspecies very precisely in the Mackenzie River delta. One locality, Tsiigehtchic, houses both subspecies (Fig. 3, Online Resource Fig. S1). Only L. l. maculosa is found in the river and lakes upriver of that locality. All populations downriver of Tsiigehtchic are exclusively $L$. l. lota. All contrasts between populations of different subspecies are highly genetically differentiated at mitochondrial and nuclear markers. The lower Mackenzie River delta, which may be a suture zone, thus represents a discrete parapatric distribution of subspecies with a short, abrupt contact zone with little hybridization. 
Low and asymmetric admixture between subspecies

The level of admixture between the two burbot subspecies in their only known location of contact is low and asymmetric. Lota l. maculosa gene flow stops abruptly at Tsiigehtchic, with no haplotype sharing and negligible admixture at microsatellite loci into the $L$. l. lota populations (Fig. 4). Conversely, we find moderate levels of introgression of L. l. lota mtDNA into L. l. maculosa, petering out as far upstream as Slave River (NWT-Alberta border) (Fig. 1). This pattern is also reflected in decreased levels of admixture between species with increasing geographic distance from the contact zone (Fig. 3). Previous research identified some asymmetry in admixture without sampling the contact zone, with some nuclear signal of $L$. l. maculosa in Yukon's Lake Laberge yet no integration of $L$. l. maculosa haplotypes into primarily $L$. l. lota populations (Elmer et al., 2008). However, earlier sampling was too geographically widespread to identify or locate the contact zone.

This pattern of asymmetric admixture, with gene flow from $L$. $l$. lota to $L$. $l$. maculosa and not in the reverse direction, suggests that some reproductive barrier to admixture may exist between subspecies. Otherwise, with equal fitness and no competition, the two subspecies would be expected to collapse into broad sympatry (Barton \& Hewitt, 1985). Asymmetric admixture from L. l. lota into L. l. maculosa could also be explained if, for example, female $L$. l. lota disperse and breed in L. l. maculosa populations. However, we find no evidence for sex-biased dispersal by female or male burbot. Potential reasons for genetic isolation may be ecological, genetic or historical, and we discuss these in turn.

It is possible that L. l. lota and L. l. maculosa have diverged in reproductive ecology to the point where there is a weak reproductive barrier between species. For example, even minor deviations in timing, location, or behaviour of breeding would impede gene flow between species by prezygotic isolation. Knowledge of reproductive ecology for these subspecies is slim (McPhail \& Paragamian, 2000), however, largely because mating occurs deep in the water under ice. More research into breeding ecology and genetics would be critical to understanding the basis of subspecies differentiation.
Ecological competition, strong local adaptation, and/or prezygotic reproductive isolation are ecological factors that may be keeping the subspecies genetically isolated. Barriers to gene flow tend to be asymmetric when there is a difference in fitness between groups (Barton \& Hewitt, 1985) or expanding populations of ecologically similar taxa meet (e.g. Stamford \& Taylor, 2004; Elmer et al., 2008). For example, Lu et al. (2001) identified variable levels of introgression among glacial refugial groups of whitefish and argued that this reflected differential impacts of natural selection stemming from the use of different environments.

However, neutral population genetic patterns and population history can also result in signals of low asymmetric admixture. For example, when two incompletely reproductively isolated species meet by range expansion, asymmetric introgression is expected to occur from the resident species to the colonising species (Petit \& Excoffier, 2009). The signal of inter(sub)specific gene flow is expected to be low because high interpopulation gene flow within subspecies results in low genetic drift and introgressing alleles are less likely to be fixed. In the instance of a high gene flow species such as burbot, this may suggest that after the last glacial maximum $L$. l. lota from the Beringian refuge arrived to the Mackenzie delta first, either by eastward migration along the Arctic Ocean coast or by some inland route that no longer exists. A waterfall is proposed to have existed on the lower Mackenzie river from 11.5 to 6.1 kya (Rempel \& Smith, 1998) and the region has a dynamic physical and glacial history (Murton et al., 2010), which may have prevented upstream migration of $L . l$. lota until after the more southern L. l. maculosa population was already established in that waterway. Such an historical pattern may result in the low genetic admixture we find without appealing to ecological barriers.

Alternatively, it is also possible that there are postzygotic barriers to hybridization between subspecies, such as genetic or cytonuclear incompatibilities (Dowling et al., 2008) or decreased hybrid fitness (Barton \& Hewitt, 1985). Such a divergence may have accumulated during the long isolation during earlier glacial times and now result in a significant barrier to gene flow (Presgraves, 2010). In other, less diverged lineages of freshwater fishes, it has been shown that hybridization affects gene expression, suggesting that 
postzygotic isolation plays a role in maintaining divergence (e.g. Whiteley et al., 2008; Mavarez et al., 2009; Renault et al., 2009). Despite the importance that determining the source of reproductive isolation between burbot subspecies has for conservation, fisheries and postglacial evolutionary biology, we know of no data or experiments on fitness in the subspecies nor hybrids.

\section{Morphological differences between subspecies}

We identified morphological differences between burbot from different localities in the Mackenzie basin. In particular, fishes from the southern reaches of our sampling (GSL and SR) were shorter in total length compared to the populations from the delta (Fig. 4). However, we did not find that the proportion of an individual that is from one subspecies or another influences size. It is possible that more detailed sampling within and among regions will identify a difference in size that relates to subspecies. Fisher et al. (1996) conducted a continent-wide weightlength analysis of burbot, not splitting subspecies, from a variety of habitats and concluded that fishes from riverine and reservoir environments have proportionally lower weights than lacustrine populations. Body shape and meristic analyses are also needed to identify if there are differences between the subspecies.

Females were larger than males, unlike burbot in Lake Superior for which Bailey (1972) found no difference in size between males and females. This may allude to further intrasubspecific variation across the L. l. maculosa range or habitat-specific variability.

\section{Population differentiation within species}

Indirect data from census and tracking studies indicate that there tends to be a lot of variation among individuals in dispersal for burbot (reviewed in McPhail \& Paragamian, 2000; Dunningan \& Sinclair, 2007); some individuals remain relatively sedentary throughout the year while other individuals have been found to disperse more than $60 \mathrm{~km}$ (Dunningan \& Sinclair, 2007) and even hundreds of kilometres (Breeser et al., 1988). Our direct findings from population genetics indicate high levels of gene flow within burbot subspecies at fine spatial scales (Fig. 3). This suggests low population structure and either that there is a common spawning ground for all populations of L. l. lota sampled or that there is no philopatry or population structuring and instead complete panmixia. In $L$. $l$. maculosa genetic differentiation increases at broader geographic scales, consistent with very low levels of isolation-by-distance.

\section{Conclusions}

Hewitt (2004) argued that suture zones would provide excellent opportunities to study reinforcement, reproductive isolation and historical effects on contemporary biodiversity. Our analysis of burbot in the Mackenzie River demonstrates that the lower delta is the contact zone between subspecies and lends support to the hypothesis that this is a 'suture zone'. At this contact zone, genetic markers suggest the burbot subspecies admix weakly and asymmetrically while gene flow within species is high. We suggest that there are some ecological and/or genetical factors impeding gene flow and maintaining subspecies' distinctiveness at the contact zone.

Acknowledgements This research was financially supported by Gwich'in Renewable Resource Board, Aurora Research Institute, Environment Canada's Northern Ecosystem Initiative, Fisheries and Oceans Canada, NSERC, DFG and the University of Konstanz. We thank M. Evans and J. Keating (Environment Canada) for contributing samples, the local fish monitors that assisted with collection and sampling (Louis Cardinal, Cecil Andre, Wally Tyrell, Russel Andre, Jozef Carnogurski, Randy Firth, Lyle Gully, Willy Clark, George Niditchie, Johnnie Kay and $\mathrm{Ab}$ Peterson), and the youth in Aklavik (Graham MacDonald, Annie Tyrell and Billy Tyrell) who assisted with sampling. We especially thank B. Dokum for technical help with sampling and assisting in the field. N. Millar also provided assistance in planning the project and assistance in the field. A special thanks to M. Evans for her assistance and comments on the manuscript and to Dr. T. Dick for his assistance throughout the project. We thank R. Eckmann for advice and assistance on morphology analyses.

\section{References}

Abbott, R. J., L. C. Smith, R. I. Milne, R. M. M. Crawford, K. Wolff \& J. Balfour, 2000. Molecular analysis of plant migration and refugia in the Arctic. Science 289: 1343.

Bailey, M. M., 1972. Age, growth, reproduction, and food of the burbot, Lota lota (Linnaeus), in southwestern Lake Superior. Transactions of the American Fisheries Society 4: 667-674. 
Barluenga, M., M. Sanetra \& A. Meyer, 2006. Genetic admixture of burbot (Teleostei: Lota lota) in Lake Constance from two European glacial refugia. Molecular Ecology 15: 3583-3600.

Barton, N. H. \& G. M. Hewitt, 1985. Analysis of hybrid zones. Annual Review of Ecology and Systematics 16: 113-148.

Bernatchez, L. \& C. C. Wilson, 1998. Comparative phylogeography of Nearctic and Palearctic fishes. Molecular Ecology 7: 431-452.

Breeser, S. W., F. D. Stearns, M. W. Smith, R. L. West \& J. B. Reynolds, 1988. Observations of movements and habitat preferences of burbot in an Alaskan glacial river system. Transactions of the American Fisheries Society 117: 506-509.

Brunhoff, C., K. E. Galbreath, V. B. Fedorov, J. A. Cook \& M. Jaarola, 2003. Holarctic phylogeography of the root vole (Microtus oeconomus): implications for late Quaternary biogeography of high latitudes. Molecular Ecology 12: 957-968.

Clement, M., D. Posada \& K. A. Crandall, 2000. TCS: a computer program to estimate gene genealogies. Molecular Ecology 9: 1657-1659.

Crawley, M. J., 2007. The R Handbook. Wiley, New York.

Dowling, D. K., U. Friberg \& J. Lindell, 2008. Evolutionary implications of non-neutral mitochondrial genetic variation. Trends in Ecology \& Evolution 23: 546-554.

Dunningan, J. L. \& C. L. Sinclair, 2007. Home range and movement patterns of burbot in Koocanusa Reservoir, Montana, USA. American Fisheries Society Symposium 59: 43-54.

Elmer, K. R., J. K. Van Houdt, A. Meyer \& F. A. M. Volckaert, 2008. Population genetics of North American burbot (Lota lota maculosa) across the Nearctic and at its contact zone with Eurasian burbot (Lota lota lota). Canadian Journal of Fisheries and Aquatic Sciences 65: 2412-2426.

Excoffier, L., L. G. Laval \& S. Schneider, 2005. Arlequin ver. 3.0: An integrated software package for population genetics data analysis. Evolutionary Bioinformatics Online 1: 47-50.

Falush, D., M. Stephens \& J. K. Pritchard, 2003. Inference of population structure using multilocus genotype data: linked loci and correlated allele frequencies. Genetics 164: 1567-1587.

Favre, L., F. Balloux, J. Goudet \& N. Perrin, 1997. Femalebiased dispersal in the monogamous mammal Crocidura russula: evidence from field data and microsatellite patterns. Proceedings of the Royal Society of London Series B 264: 127.

Fedorov, V. B. \& N. C. Stenseth, 2002. Multiple glacial refugia in the North American Arctic: inference from phylogeography of the collared lemming (Dicrostonyx groenlandicus). Proceedings of the Royal Society of London Series B 269: 2071.

Fedorov, V. B., A. V. Goropashnaya, M. Jaarola \& J. A. Cook, 2003. Phylogeography of lemmings (Lemmus): no evidence for postglacial colonization of Arctic from the Beringian refugium. Molecular Ecology 12: 725-731.

Fisher, S. J., D. W. Willis \& K. L. Pope, 1996. An assessment of burbot (Lota lota) weight-length data from North American populations. Canadian Journal of Zoology 74: 570-575.
Google Corporation, 2007. Google Earth Version 4.2 [available on internet at http://earth.google.com/intl/en/]

Goudet, J., 1995. Fstat version 1.2: a computer program to calculate F-statistics. Journal of Heredity 86: 485-486.

Gum, B., R. Gross \& R. Kuehn, 2005. Mitochondrial and nuclear DNA phylogeography of European grayling (Thymallus thymallus): evidence for secondary contact zones in central Europe. Molecular Ecology 14: 1707-1725.

Hewitt, G. M., 2001. Speciation, hybrid zones and phylogeography - or seeing genes in space and time. Molecular Ecology 10: 537-540.

Hewitt, G. M., 2004. The structure of biodiversity-insights from molecular phylogeography. Frontiers in Zoology 1: 4 .

Holder, K., R. Montgomerie \& V. L. Friesen, 1999. A test of the glacial refugium hypothesis using patterns of mitochondrial and nuclear DNA sequence variation in rock ptarmigan (Lagopus mutus). Evolution 53: 1936-1950.

Holder, K., R. Montgomerie \& V. L. Friesen, 2000. Glacial vicariance and historical biogeography of rock ptarmigan (Lagopus mutus) in the Bering region. Molecular Ecology 9: 1265-1278.

Kalinowski, S. T., 2005. HP-Rare 1.0: a computer program for performing rarefaction on measures of allelic richness. Molecular Ecology Notes 5: 187-189.

Larkin, M. A., G. Blackshields, N. P. Brown, R. Chenna, P. A. McGettigan, H. McWilliam, et al., 2007. Clustal W and Clustal X version 2.0. Bioinformatics 23: 2947-2948.

Lu, G., D. J. Basley \& L. Bernatchez, 2001. Contrasting patterns of mitochondrial DNA and microsatellite introgressive hybridization between lineages of Lake Whitefish (Coregonus clupeaformis); relevance for speciation. Molecular Ecology 10: 965-985.

Mavarez, J., C. Audet \& L. Bernatchez, 2009. Major disruption of gene expression in hybrids between young sympatric anadromous and resident populations of brook charr (Salvelinus fontinalis Mitchill). Journal of Evolutionary Biology 22: 1708-1720.

McCrimmon, H. R., 1959. Observations on spawning of burbot in Lake Simcoe, Ontario. Journal of Wildlife Management 23: 447-449.

McDermid, J. L., J. D. Reist \& R. A. Bodaly, 2007. Phylogeography and postglacial dispersal of whitefish (Coregonus clupeaformis complex) in Northwestern North America. Advances in Limnology 60: 91-109.

McPhail, J. D. \& C. C. Lindsey, 1970. Freshwater Fishes of Northwestern Canada and Alaska. Bulletin No. 173. Fisheries Research Board of Canada, Ottawa.

McPhail, J. D. \& V. L. Paragamian, 2000. Burbot biology and life history. Transactions of the American Fisheries Society 128: 11-23.

Meyer, A., J. M. Morrissey \& M. Schartl, 1994. Recurrent origin of a sexually selected trait in Xiphophorus fishes inferred from a molecular phylogeny. Nature 368: 539-542.

Miler, O. \& P. Fischer, 2004. Distribution and onshore migration behaviour of burbot larvae in Lake Constance, Germany. Journal of Fish Biology 64: 176-185.

Murton, J. B., M. D. Bateman, S. R. Dallimore, J. T. Teller \& Z. Yang, 2010. Identification of younger Dryas outburst flood path from Lake Agassiz to the Arctic Ocean. Nature 464: 740-743. 
Nesbø, C. L., T. Fossheim, L. A. Vøllestad \& K. S. Jakobsen, 1999. Genetic divergence and phylogeographic relationships among European perch (Perca fluviatilis) populations reflect glacial refugia and postglacial colonization. Molecular Ecology 8: 1387-1404.

Peakall, R. \& P. E. Smouse, 2006. GENALEX 6: genetic analysis in Excel, Population genetic software for teaching and research. Molecular Ecology Notes 6: 288-295.

Petit, R. J. \& L. Excoffier, 2009. Gene flow and species delimitation. Trends in Ecology \& Evolution 24: 386-393.

Pielou, E. C., 1991. After the Ice Age: The Return of Life to Glaciated North America. University of Chicago Press, Chicago.

Pivnicka, K., 1970. Morphological variation in the burbot (Lota lota) and recognition of the subspecies: a review. Journal of the Fisheries Research Board of Canada 27: 1757-1765.

Powell, M., V. L. Paragamian \& J. Dunnigan, 2008. Mitochondrial variation in western North American burbot with special reference to the Kootenai River in Idaho and Montana. American Fisheries Society Symposium 59: 3-27.

Presgraves, D. C., 2010. The molecular evolutionary basis of species formation. Nature Reviews Genetics 11: 175.

Pritchard, J. K., M. Stephens \& P. Donnelly, 2000. Inference of population structure using multilocus genotype data. Genetics 155: 945-959.

Raymond, M. \& F. Rousset, 1995. GENEPOP, version 1.2: population genetics software for exact tests and ecumenicism. Journal of Heredity 86: 248-249.

Remington, C. L., 1968. Suture-zones of hybrid interaction between recently joined biotas. Evolutionary Biology 2: $321-428$.

Rempel, L. L. \& D. G. Smith, 1998. Postglacial fish dispersal from the Mississippi refuge to the Mackenzie River basin. Canadian Journal of Fisheries and Aquatic Sciences 55: 893-899.

Renault, S., A. W. Nolte \& L. Bernatchez, 2009. Gene expression divergence and hybrid misexpression between Lake Whitefish species pairs (Coregonus spp. Salmonidae). Molecular Biology and Evolution 26: 925-936.

Rousset, F., 1997. Genetic differentiation and estimation of gene flow from F-statistics under isolation by distance. Genetics 145: 1219-1228.

Sanetra, M. \& A. Meyer, 2005. Microsatellites from the burbot (Lota lota), a freshwater gadoid fish (Teleostei). Molecular Ecology Notes 5: 390-392.

SAS, 2008. JMP Ver. 5. SAS Institute Inc, Cary.
Scott, W. B. \& E. J. Crossman, 1973. Freshwater fishes of Canada. Fisheries Research Board of Canada Bulletin 184: $1-966$.

Slavík, O. \& L. Bartoš, 2002. Factors affecting migrations of burbot. Journal of Fish Biology 60: 989-998.

Slavík, O., L. Bartoš \& D. Mattas, 2005. Does stream morphology predict the home range size in burbot? Environmental Biology of Fishes 74: 89-98.

Squires, M. M., L. F. W. Lesack, R. E. Hecky, S. J. Guildford, P. Ramlal \& S. N. Higgins, 2009. Primary production and carbon dioxide metabolic balance of a lake-rich arctic rive floodplain: Partitioning of phytoplankton, epipelon, macrophyte, and epiphyton production among lakes on the Mackenzie delta. Ecosystems 12: 853-872.

Stamford, M. D. \& E. B. Taylor, 2004. Phylogeographical lineages of Arctic grayling (Thymallus arcticus) in North America: divergence, origins and affinities with Eurasian Thymallus. Molecular Ecology 13: 1533-1549.

Stepien, C. A. \& J. E. Faber, 1998. Population genetic structure, phylogeography and spawning philopatry in walleye (Stizostedion vitreum) from mitochondrial DNA control region sequences. Molecular Ecology 7: 1757-1769.

Swenson, N. G. \& D. J. Howard, 2004. Do suture zones exist? Evolution 58: 2391-2397.

Swofford, D. L., 2003. PAUP*. Sinauer Associates, Sunderland.

Turgeon, J. \& L. Bernatchez, 2001. Mitochondrial DNA phylogeography of Lake Cisco (Coregonus artedi): evidence supporting extensive secondary contacts between two glacial races. Molecular Ecology 10: 987-1001.

Van Houdt, J. K., B. Hellemans \& F. A. M. Volckaert, 2003. Phylogenetic relationships among Palearctic and Nearctic burbot (Lota lota): Pleistocene extinctions and recolonization. Molecular Phylogenetics and Evolution 29: 599-612.

Van Houdt, J. K. J., L. de Cleyn, A. Perretti \& F. A. M. Volckaert, 2005. A mitogenic view on the evolutionary history of the Holarctic freshwater gadoid, burbot (Lota lota). Molecular Ecology 14: 2445-2457.

van Oosterhout, C., W. F. Hutchison, D. P. M. Wills \& P. Shipley, 2004. Micro-checker: software for identifying and correcting genotyping errors in microsatellite data Molecular Ecology Notes 4: 535-538.

Whiteley, A. R., N. Derome, S. M. Rogers, J. St-Cyr, J. Laroche, A. Labbe, et al., 2008. The phenomics and expression quantitative trait locus mapping of brain transcriptomes regulating adaptive divergence in Lake Whitefish species pairs (Coregonus sp.). Genetics 180: 147-164. 